\title{
Current Topics on Cancer Stem Cell Associated Melanoma Treatment Researches
}

\author{
Kubilay Doğan Kılıç ${ }^{1}$, Hatice K Başaloğlu² ${ }^{2}$ Yiğit Uyanikgil ${ }^{1,3}$ and Mehmet Turgut ${ }^{4^{*}}$ \\ 1Department of Histology and Embryology, Ege University, School of Medicine, Izmir, Turkey \\ 2Department of Histology and Embryology, Adnan Menderes University School of Medicine, Aydın, Turkey \\ 3Cord Blood, Cell-Tissue Research and Application Center, Ege University, Izmir, Turkey \\ 3Department of Neurosurgery, Adnan Menderes University School of Medicine, Aydın, Turkey \\ 4Department of Neurosurgery, Adnan Menderes University School of Medicine, 09100 Aydın, Turkey
}

${ }^{*}$ Corresponding author: Mehmet Turgut, Associate Professor of Neurosurgery, Department of Neurosurgery, Adnan Menderes University School of Medicine, 09100 Aydın, Turkey, Tel: +90 256 2134874; Fax: +90 256 2120146; E-mail: drmturgut@yahoo.com

Received date: 02 January 2017; Accepted date: 23 January 2017; Published date: 31 January 2017

Copy right: $\odot 2016$ Turgut $\mathrm{M}$, et al. This is an open-access article distributed under the terms of the Creative Commons Attribution License, which permits unrestricted use, distribution, and reproduction in any medium, provided the original author and source are credited.

\section{Melanoma Treatment}

Malignant tumor of melanocytes describes as "melanoma". Melanocytes are derived from the neural crest and make the pigment melanin [1]. Despite most melanomas emerge in the skin, they may arise on mucosal surfaces or eyes and rarely intestines. A common point of these organs is the migration of neural crest cells [2,3]. An expected 13.7 million Americans with cancer background were alive on 2012. In the same report, in 2022, it is expected that number will increase approximately 18 million. It makes melanoma the $3 \mathrm{rd}$ most prevalent cancers among males [4]. The risk factors are environmental factors, family history, characteristics of pigment, multiple nevi, immunosuppression and genetic factors [5,6].

We should understand the importance of the relation between cancer stem cells and genetic regulations to develop a therapy. Stem cells are defined as cells that have the ability to immortalize themselves through self-renewal and to differentiate to mature cell of significant tissue. However, there are also cancer stem cells within definite proliferative potential and ability to growth tumors [7]. Rare stem cells which may cause cancer are related with genes. Most importantly, most frequent mutations in cutaneous melanoma appear in BRAF (V-raf murine sarcoma viral oncogene homolog B1) genes [8]. Nearly, up to $60 \%$ of malignant melanomas generates from a single transition in BRAF [9]. Lessly NRAS (neuroblastoma RAS viral [v-ras] oncogene homolog), c-KIT, CDK4 are responsible, too $[10,11]$.

Researches are focused on four main topics: transcriptional response, tumor microenvironment, marker and pathways [12-15]. Following novel ones choosen to represent each topic.

Chen et al. turned their way to nature. They suggested that a licorice extract: Isoliquiritigenin (ISL) may cause B16F0 melanoma cell differentiation. Here, researchers investigated the differentiation process of the transcriptional response of ISL-inducing. They searched for 390 genes which have roles in 201 biochemical pathways and found out altered expression levels in ISL treatment. Different expression of anti-proliferative and differentiation inducing genes indicated malignancy loss [12].

Findings of studies suggest that Ipilimumab plus bevacizumab therapy supports immunity in the tumor microenvironment via enhanced lymphocyte infiltration and antibody responses [13,14]. IL1 alpha, TNF-alpha, and CXCL10, with VEGF neutralization, contribute to ipilimumab plus bevacizumab-induced melanoma immune recognition [15]. CD271 is a neurotrophin receptor. It expresses in melanoma. Saltari et al. investigated CD271 characteristics extensively. They found following results in zebrafish in vitro: CD271 overexpression in SKMEL28 cells reduced invasion, CD271 overexpressing $1205 \mathrm{Lu}$ cells was in a relationship with fewer metastases percentage, the absence of CD271 caused reduced cell-cell adhesion. All of them indicate that loss of CD271 is crucial for melanoma metastasis and progression [16]. Surveys showed that CD271-positive melanoma stem cells showed correlations with metastasis, not prognosis in humans. These cells are multipotent and can create heterogeneity tumor after maturity In vivo they have self-renewal capacity and maintain tumor growth $[17,18]$.

Notch and ERBB are essential for melanocyte precursors. In their study Zhang et al. show that in mutated and wild-type BRAF melanomas; active Notch1 and active ERBB3, ERBB2 correlates and expression levels are similar [19]. Blocking Notch and ERBB signaling at the same time, inhibits the slow cycling of JARID1B+ cell population. Due to JARID1B+cells represent cancer stem cells, this is crucial for melanoma growth continuation in long term [20]. Kaushik et al. also reported that Notch2 pathway is effective on melanoma. As a result, these results propose regulating these pathways is an advance way for melanoma treatment [19].

Today, there are more researches on the pathway, tumor microenvironment, and marker. The information obtained from these studies may lead to the emergence of new treatment strategies and activities of therapeutic agents. These research examples are the pioneers, and potentially have high impact.

\section{References}

1. Mort RL, Jackson IJ, Patton EE (2015) The melanocyte lineage in development and disease. Development 142: 620-632.

2. Schoenfield L (2014) Uveal melanoma: A pathologist's perspective and review of translational developments. Adv in Anatomicpathol 21: 138-143.

3. Lens M, Bataille V, Krivokapic Z (2009) Melanoma of the small intestine. The Lancet Oncol 10: 516-521.

4. Siegel R, DeSantis C, Virgo K, Stein K, Mariotto A, et al. (2012) Cancer treatment and survivorship statistics. CA: a cancer $\mathrm{j}$ for clinicians 62 : 220-241.

5. Bakos L, Wagner M, Bakos RM, Leite CS, Sperhacke CL, et al. (2002) Sunburn, sunscreens, and phenotypes: some risk factors for cutaneous melanoma in southern Brazil. International J Dermatol 41: 557-562.

6. Veierod MB, Adami HO, Lund E, Armstrong BK, Weiderpass E (2010) Sun and solarium exposure and melanoma risk: effects of age, pigmentary 
Citation: Kiliç KD, Basaloglu HK, Uyanikgil Y, Turgut M (2017) Current Topics on Cancer Stem Cell Associated Melanoma Treatment Researches . J Brain Tumors Neurooncol 2: 1000112. doi:10.4172/2475-3203.1000112

Page 2 of 2

characteristics, and nevi. Cancer Epidemiology Biomarkers \& Prevention 19: 111-120.

7. Reya T, Morrison SJ, Clarke MF, Weissman IL (2001) Stem cells, cancer, and cancer stem cells. Nature 414: 105-111.

8. Davies H, Bignell GR, Cox C, Stephens P, Edkins S, et al. (2002) Mutations of the BRAF gene in human cancer. Nature 417: 949-954.

9. Garnett MJ, Marais R (2004) Guilty as charged: B-RAF is a human oncogene. Cancer cell 6: 313-319.

10. Dicker AP, Volkenandt M, Albino AP (1990) Mutation alanalysis of human NRAS genes in malignant melanoma: rapid methods for oligonucleotide hybridization and manual and automated direct sequencing of products generated by the polymerase chain reaction. Genes, Chromosomes and Cancer 1: 257-269.

11. Lassam N, Bickford S (1992) Loss of c-kit expression in cultured melanoma cells. Oncogene 7: 51-56

12. Chen X, Yang M, Hao W, Han J, Ma J, et al. (2016) Differentiationinducing and anti-proliferative activities of isoliquiritigenin and all-transretinoicacid on B16F0 melanoma cells: Mechanisms profiling by RNAseq. Gene 592: 86-98.

13. Carter T, Shaw H, Cohn-Brown D, Chester K, Mulholland P (2016) Ipilimumab and Bevacizumab in Glioblastoma. Clinical Oncology 28: 622-626.

14. Moser JC, Pulido JS, Dronca RS, McWilliams RR, Markovic SN, et al. (2015) The Mayo Clinic experience with the use of kinase inhibitors, ipilimumab, bevacizumab, and local therapies in the treatment of metastatic uveal melanoma. Melanoma research, 25: 59-63.
15. Wu X, Hurder GA, Liao X, Lawrence D, McDermott D, etal. (2016) VEGF neutralization plus CTLA-4 blockade alters soluble and cellular factors associated with enhancing lymphocyte infiltration and humoral recognition in melanoma. Cancer Immunology Research, 4: 858-868.

16. Saltari A, Truzzi F, Quadri M, Lotti R, Palazzo E, et al. (2016) CD271 Down-regulation promotes melanoma progressionandInvasion in ThreeDimensionalModelsand in Zebrafish. Journal of Investigative Dermatology 136: 2049-2058.

17. Gambichler T, Petig AL, Stockfleth, E, Stücker M (2016) Expression of SOX10, ABCB5 and CD271 in melanocytic lesions and correlation with survival data of patients with melanoma. Clinical and Experimental Dermatology 41: 709-716.

18. Civenni G, Walter A, Kobert N, Probst DM, Zipser M, et al. (2011) Human CD271-positive melanoma stem cells associated with metastasis establish tumor heterogeneity and long-term growth. Cancer research 71 : 3098-3109.

19. Zhang K, Wong P, Salvaggio C, Salhi A, Osman I, et al. (2016) Synchronized targeting of Notch and ERBB signaling suppresses melanoma tumor growth through inhibition of Notch1 and ERBB3. J of Investigative Dermatology 136: 464-472.

20. Kaushik G, Venugopal A, Ramamoorthy P, Standing D, Subramaniam D, et al. (2015) Honokiol inhibits melanoma stem cells by targeting notch signaling. Molecular carcinogenesis 54: 1710-1721. 